
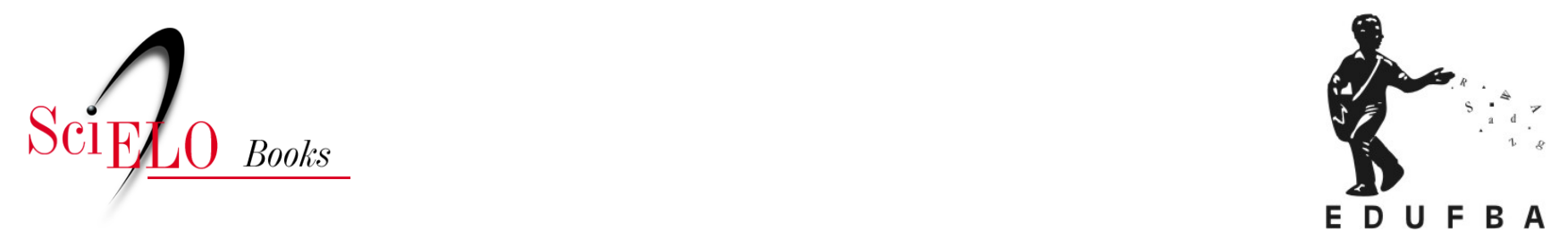

\title{
As artes urbanas de Parintins associadas à festa do boi bumbá uma análise de suas representações figurativas
}

\author{
Marivaldo Bentes da Silva
}

\section{SciELO Books / SciELO Livros / SciELO Libros}

SILVA, M.B. As artes urbanas de Parintins associadas à festa do boi bumbá: uma análise de suas representações figurativas. In: HERNÁNDEZ, M.H.O., and LINS, E.Á., eds. Iconografia: pesquisa e aplicação em estudos de Artes Visuais, Arquitetura e Design [online]. Salvador: EDUFBA, 2016, pp. 150-167. ISBN: 978-85-232-1861-4. https://doi.org/10.7476/9788523218614.0010.

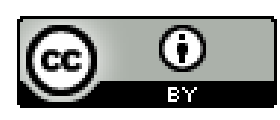

All the contents of this work, except where otherwise noted, is licensed under a Creative Commons Attribution $\underline{4.0 \text { International license. }}$

Todo o conteúdo deste trabalho, exceto quando houver ressalva, é publicado sob a licença $\underline{\text { Creative Commons }}$ Atribição 4.0. 
As artes urbanas de Parintins associadas à festa do boi-bumbá: uma análise de suas representações figurativas

Marivaldo Bentes da Silva 


\section{Considerações iniciais}

$\mathrm{J}$

á há algumas décadas, a rivalidade entre os grupos de bumbás Garantido e Caprichoso, que constituem a expressão máxima da manifestação do boi-bumbá na cidade de Parintins e, sem exageros, no estado do Amazonas, vem alimentando um criativo, dinâmico e ininterrupto processo de estetização do espaço urbano, empreendido voluntariamente pelos moradores, que assumiram as artes públicas como canais privilegiados de expressão de suas preferências em termos de grupo de bumbá e, portanto, de definição de seu lugar no contexto da disputa. São inúmeras e distintas realizações com propósitos estéticos e artísticos, como bandeiras, faixas, painéis pintados e esculpidos, que fazem uso exaustivo da figura do coração e das cores vermelho e branco, quando empreendidas por torcedores do boi Garantido, ou da imagem da estrela e das cores azul e branco, quando o bumbá em questão é o Caprichoso. A densidade dessas realizações e também de pessoas que se ocupam de sua produção e manutenção, pontos que discutiremos mais adiante, nos habilita a pensar este processo de estetização como "movimento", cuja diversidade de interesses não impede que a cidade seja lida como uma espécie de prolongamento da festa, com todas as suas convenções e excessos característicos. 
Em virtude de sua incontestável ligação com a festa, as intervenções feitas no espaço urbano pelos torcedores dos bumbás, em geral, são percebidas, analisadas e valorizadas apenas como elementos de decoração e entretenimento, que materializam os diferentes níveis de envolvimento dos moradores com a disputa. Poucas vezes, foram pensadas como portadoras de significados e mensagens que, embora não tendo precedência sobre as noções de rivalidade, competição, espetacularidade, visibilidade e divertimento, ajudam a construir outras compreensões dos grupos que as produzem. Mesmo aquelas realizações mais sofisticadas e complexas, como os painéis pintados e esculpidos, em que o conjunto básico de motivos iconográficos se enriquece com a introdução de outros temas, reclamam por análises interessadas em justificativas menos práticas para sua presença no contexto parintinense.

Envolvidos na busca por novos prismas de interpretação das artes urbanas associadas aos bumbás Garantido e Caprichos, ${ }^{1}$ propomos aqui sua análise à luz do Método Iconográfico, do crítico e historiador de arte alemão Erwin Panofsky (1892-1968). Segundo Panofsky (2004), a iconografia é uma prática de erudição por excelência, consistindo na catalogação, exame e descrição da ocorrência de certos elementos visuais. É uma disciplina, acima de tudo, descritiva. Já a iconologia apresenta-se como um método histórico, que tem por objetivo fazer a "síntese" dos dados obtidos por uma análise iconográfica. Em poucas palavras, enquanto a iconografia se prestaria à explicitação do tema de uma obra de arte, a iconologia seria capaz de fornecer o "significado" deste tema, isto é, construir um discurso capaz de apresentar a história daquele tema.

O método, instrumentalizado por Panofsky, é constituído de três níveis de análise: o "nível primário" (pré-iconográfico ou natural), que se caracteriza pela percepção da obra em sua forma pura e pela mera descrição daquilo que é imediatamente apreensível; o "nível secundário" (iconográfico ou convencional), centrado na equação cultural e conhecimento iconográfico; e o "nível terciário" (iconológico ou dos princípios culturais “subjacentes”), que recorre à história pessoal, técnica e cultural para o entendimento de uma obra. Com efeito, o cumprimento de cada nível coloca a arte em uma posição cada vez mais distante da noção de incidente isolado e próxima da realidade de produto de um ambiente histórico. Ao mesmo tempo, confirma a análise do fenômeno artístico como um empreendimento intelectual, que se opõe à suposição de que a obra artística, em

\footnotetext{
1 Sentenças como esta, que deixam clara a vinculação das intervenções urbanas aqui destacadas com a rivalidade entre os grupos Garantido e Caprichoso, serão recorrentes neste texto, visto que no espaço urbano de Parintins registra-se não apenas a presença de realizações associadas à festa, mas também de outras que, embora influenciadas pela técnica, estilo e temas das primeiras, são produzidas a partir de interesses, por assim dizer, extrínsecos ao evento. Portanto, ao fazer uso de sentenças afirmativas da relação de determinadas intervenções com a festa, pretendemos deixar claros os limites de nosso objeto de estudo.
} 
sua materialidade, é capaz de oferecer todas as informações necessárias ao entendimento de sua expressividade e ocorrência.

Devemos esclarecer que, embora o método panofskyano consista em etapas sequenciadas de análise, situadas dentro de uma lógica de compreensão da obra artística, nossa investida - um ensaio, na realidade, que pretende abrir caminho para estudos mais aprofundados - se caracterizará pelo uso livre do método, tomando-o, antes de tudo, como apoio à construção de uma leitura das artes urbanas associadas à festa dos bumbás, em que possam ser evidenciados seus significados e possíveis mensagens.

Esclarecemos também que, aqui, serão priorizados os painéis pintados e esculpidos, que costumam comparecer em fachadas, frontões e muros de residências e unidades comerciais. Sendo estas as realizações mais ambiciosas, em termos de representação figurativa, cremos que a busca por significados e mensagens poderá ser mais frutífera.

\section{Rivalidade festiva e estetização da cidade}

$\mathrm{O}$ estudo das artes urbanas parintinenses, associadas à festa de Garantido e Caprichoso, exige que façamos uma breve incursão nos fatores geradores de sua ocorrência, especificamente nas apropriações da rivalidade existente entre os referidos bumbás pelos parintinenses.

O espírito de rivalidade é, certamente, o aspecto mais marcante do estado atual da festa dos bumbás Garantido e Caprichoso, e também aquele que teve maior influência na construção de uma relação de dependência entre estes grupos e no desdobramento de suas aparições públicas para um horizonte cada vez mais espetacularizado e massificado. É esta rivalidade, somada à vontade de conquista do título de campeão, que estimula gestores, pesquisadores, técnicos e artistas ligados aos grupos a alinharem seus esforços no sentido de aprimoramento constante das realizações artísticas, a exemplo de alegorias, indumentárias, adereços e toadas, voltadas para as apresentações na arena do bumbódromo. Esta mesma rivalidade, mais especificamente seu forte apelo popular e, portanto, comercial, é responsável por manter o interesse da mídia e dos grupos de patrocínio. A captura e manutenção do gosto e da preferência do público também são uma consequência da rivalidade e dos resultados artísticos de que falamos há pouco. Interessa-nos este último campo de influência, no caso, o plano da recepção.

O acirramento das disputas entre os bumbás Garantido e Caprichoso teve grande impacto no público, provocando o aumento considerável do número de espectadores, sua organização em torcedores do "vermelho e branco" e torcedores do "azul e branco" e o aparecimento de formas públicas de expressão de sua 
relação com a festa e, por conseguinte, com seu grupo de predileção. Sobre este último ponto, assinalamos que uma das mudanças sumárias foi a cotidianização das discussões sobre a festa, mais precisamente sobre a qualidade das apresentações, as inovações empreendidas pelos artistas, o perfil e a performance individual dos itens, ${ }^{2}$ a vitória ou derrota de determinado bumbá, entre outros assuntos que, a princípio, interessavam apenas na época do evento. Isso, inevitavelmente, fez emergir conflitos e desentendimentos entre torcedores dos grupos, que, aos poucos, conduziram a mudanças inusitadas em seu comportamento diário. Como escreve Salete Lima (1989, p. 8, grifo do autor),

[...] nas famílias numerosas, irmãos ficam de mal, pais e filhos que torcem por bois diferentes evitam falar sobre o assunto e até casais se separam. A rivalidade é tão grande que o torcedor não pronuncia sequer o nome do adversário, quando muito se refere a este de boi contrário ou simplesmente contrário.

O que tal comentário informa é que a rivalidade entre os bumbás impactou a vida dos parintinenses de modo tão profundo que as ideias de rivalidade e competitividade conseguiram se infiltrar em diferentes esferas da vida social, consolidando o "amor ao boi" e o desapreço pelo "contrário" como fundamentos de uma verdadeira visão de mundo, envolvendo formas de pensar, sentir, representar, comportar, acreditar, criar, viver e, até mesmo, morrer.

Para que não sejamos acusados de exagerados, citemos aqui o fato envolvendo D. Maria Ângela Farias, uma das personalidades femininas mais marcantes e atuantes da história do boi Garantido e da festa como um todo. Quando do seu falecimento, em meados de 2014, seu corpo foi conduzido até a igreja para a missa de corpo, acompanhado da figura do boi Alegórico e de aproximadamente quarenta ritmistas (sem tocar instrumentos), devidamente vestidos com roupas com as cores do bumbá. Este modo peculiar de rito fúnebre se mostrou inusitado para a comunidade local, já que inexistiam registros de um acontecimento similar, mas sua ocorrência não foi ridicularizada ou vista como incongruente, uma vez que todos reconheciam e admiravam o forte envolvimento de D. Maria Ângela com o Garantido.

As mudanças de comportamento, que, durante longo período, envolveram agressões verbais e físicas e até mesmo homicídios, ${ }^{3}$ representam apenas uma das interfaces da ação da festa dos bumbás sobre a sociedade parintinense, que,

2 Personagens que constituem a cênica e que são avaliados durante a apresentação. Os mais visados e comentados são Cunhã Poranga, Pajé, Porta-Estandarte, Rainha do Folclore, Sinhazinha da Fazenda e o boi Alegórico, cujos movimentos são conferidos pelo "tripa” (aquele que dança embaixo de sua estrutura).

3 Sobre a questão, recomendamos o capítulo "A rivalidade", do livro Boi-bumbá (evolução): livro-reportagem sobre o Festival Folclórico de Parintins (2006), de Allan Rodrigues. 
como anunciamos, também passou a adotar e difundir outras formas de expressão, as quais podem ser tomadas como traduções de um pensamento local, que assume os torcedores como componentes fundamentais da disputa, mesmo fora do espaço e do tempo reservados para as disputas artísticas entre os bumbás. Esse mesmo pensamento dá grande importância às atitudes e realizações dos torcedores, valorizando-as como fortes contribuintes para a projeção de seus grupos favoritos e a efervescência do evento como um todo. Entre as demais formas de expressão, interessam-nos as de caráter estético e artístico, apresentadas por Lima (1989, p. 8) na seguinte colocação:

Com a proximidade da festa, a cidade se transforma: divide-se literalmente ao meio pelas cores vermelha e azul, numa demonstração clara do confronto. Na parte alta, é o reduto do Garantido, na baixa, do Caprichoso. Quem chega de barco em Parintins pode nem entender o que representam aquelas cores, mas, desde longe, já se avista nitidamente o contraste. [...] A cidade fica repleta de bandeiras e rara é a casa que não adere a manifestação, enfeitando suas portas com a cor de sua preferência, ora com figuras de boi, ora com bandeiras.

Na passagem acima, o processo de preparação do espaço urbano para a festa, a partir da introdução de formas impregnadas de artisticidade que obedecem às suas exigências estéticas e sugestões temáticas, é apresentado como um dos traços mais expressivos do fenômeno do boi-bumbá em Parintins, ou, mais especificamente, dos novos modos de participação experimentados pelos moradores. Esse processo, fortemente sustentado por iniciativas comunitárias individuais e coletivas, ${ }^{4}$ que incidem tanto sobre o espaço privado quanto o público, tem permitido a expansão de "[...] uma rede ampla de intervenções urbanas esclarecedoras quanto ao valor da festa para os moradores da cidade, que não a valorizam apenas como espetáculo datado e dirigido a um espaço específico, cujos únicos resultados são divertimentos e rendimentos econômicos momentâneos”. (SILVA, 2009, p. 42) Pelo contrário, tanto seu evento máximo, as apresentações dos bumbás na arena do bumbódromo, no último fim de semana do mês de junho, quanto aqueles de menores proporções, que ocorrem nos momentos anterior e posterior a tal acontecimento, tais como as exibições de rua e os ensaios nos currais, são tomados como oportunidades de socialização, capazes, por exemplo, de reforçar sua

4 É preciso reconhecer a participação das associações folclóricas dos bumbás Garantido e Caprichoso na dinâmica desse movimento. Especialmente os dois painéis esculpidos do boi "azul e branco", um deles localizado na fachada principal de sua sede, na Rua Joaquim Prestes Azedo, e o seguinte, em uma das paredes laterais de seu Curral, na Rua Gomes de Castro, ambos acessíveis ao olhar externo, têm servido de referência permanente para os empreendimentos dos moradores. 
solidariedade comunitária, seu sentimento de pertencimento e orgulho identitário. A estetização da cidade, como empreendimento ligado à festa, demonstraria um valor semelhante.

É preciso retomar o comentário de Lima (1989) para pontuar que, embora seu conteúdo sugira uma condição temporária para o processo de estetização da cidade, ou seja, que a "cidade se transforma" apenas "com a proximidade da festa", o movimento aqui tratado não se restringe ao tempo festivo, ou seja, àquele período reservado ao acontecimento e seus desdobramentos imediatos, no caso, do mês de maio ao início de julho. Pelo contrário, sua ocorrência se dá ao longo do ano, de modo ininterrupto, se intensificando, naturalmente, com a chegada da festa.

O que é interessante nessa visão da "preparação do espaço urbano para a festa" como um movimento contínuo é que ela induz a um levantamento das modalidades de intervenção que o constituem e de suas qualidades específicas. O que nossas pesquisas de campo têm nos permitido verificar é que, no espaço urbano parintinense, registram-se dois grupos de intervenções com propósitos estéticos e artísticos: o primeiro é caracterizado por formas efêmeras, que ocorrem principalmente no período precedente à disputa no bumbódromo. Suas realizações mais populares são bandeiras, feitas de plástico ou Tecido Não Tecido (TNT) sintético, que aparecem dispostas em fios, formando, nas ruas, uma espécie de mapa imenso, organizado e padronizado, e as faixas de tecido, que costumam descansar nas sacadas e janelas das residências, trazendo pequenos textos que enaltecem o boi de predileção do proprietário ou provocam o boi "contrário". Bandeiras de tecido, com conteúdo similar, de médio e grande porte, sustentadas por hastes e fixadas no alto das fachadas, muros e outras áreas da edificação que lhe permitem visibilidade, também dão densidade a esse conjunto.

O segundo grupo de intervenções é identificado por realizações imbuídas de um espírito mais duradouro e que, justamente por isso, exercem especial influência na dilatação do tempo e do espaço festivos, a exemplo de painéis pintados e esculpidos (Figura 1). As especificidades dessas obras serão apresentadas na seção seguinte, no entanto, podemos adiantar que seu caráter permanente é um convite para que pensemos na capacidade que as festas possuem de se entrelaçar à existência cotidiana e, assim, gerar desdobramentos que ressaltam a força de sua presença no contexto em que ocorrem, tanto no momento precedente quanto no posterior ao tempo que lhe é reservado. No caso parintinense, a noção de participante ativo da festa se torna um estado constante, que não se fecha, como já dissemos, em um tempo e espaço determinados e, desse modo, desqualifica qualquer argumento a favor de uma oposição absoluta entre o acontecimento festivo e a vida diária. 


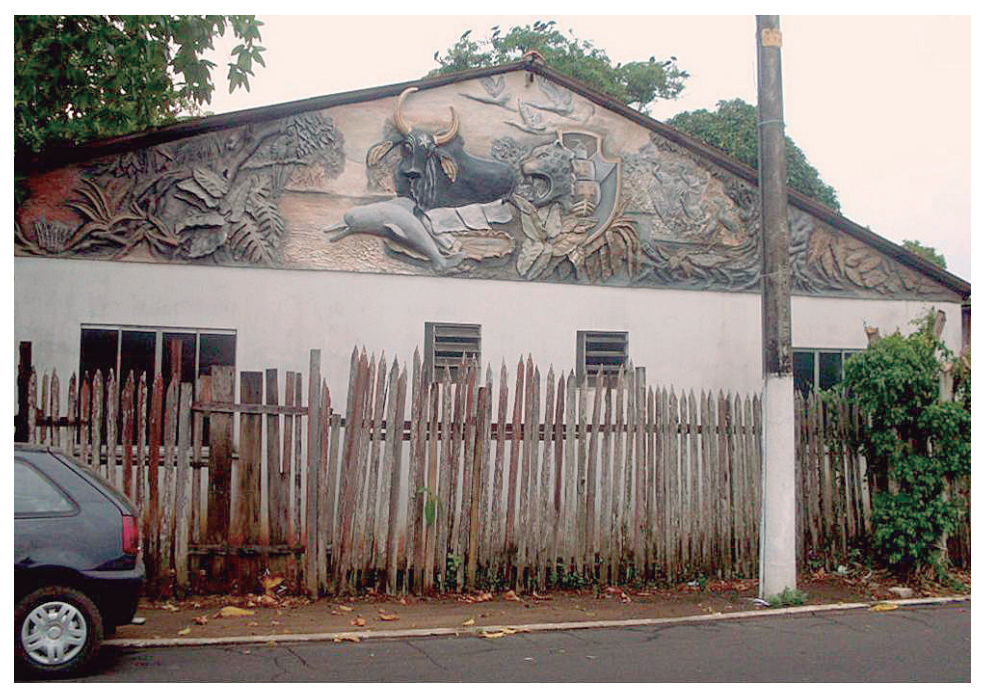

Figura 1 - Painel esculpido em frontão lateral de residência Fotografo: Leandro Bentes (2013).

Um dado importante sobre o movimento de estetização da cidade é que sua massificação, a partir da década de 1960, período em que se registra a oficialização da disputa entre Garantido e Caprichoso, desencadeou reações diversas, sobretudo entre os torcedores, cuja tentativa de dar projeção às suas preferências em termos de grupo de bumbá era vista, pelos torcedores contrários, como uma provocação pública. Ou seja, até mesmo o empreendimento de caracterização do espaço urbano, segundo a esteticidade da festa, foi impregnado com as ideias de rivalidade e competitividade, resultando, muitas vezes, em práticas de vandalismo, que culminavam em ocorrências policiais. O depoimento do procurador Carlos Coelho sobre esta problemática, na década de 1980, é esclarecedor:

Quase todos os dias, recebíamos uma denúncia de que determinada pessoa havia sido agredida ou que tinha tido a casa apedrejada em razão de sua preferência por boi. Geralmente, as vítimas eram pessoas que torciam para um bumbá, mas que moravam num local onde a maioria torcia pelo contrário. Então, o confronto tornava-se iminente e a violência era inevitável. A turma ia para briga mesmo. Depredava a fachada e o telhado da casa do contrário, arrancava as bandeiras e destruía qualquer ornamentação que lembrasse o boi rival. Diante do problema, tivemos que tomar atitude mais dura. (COELHO apud RODRIGUES, 2009, p. 110) 
A “atitude", mencionada por Carlos Coelho, consistiu na regulamentação dos trabalhos de ornamentação da cidade para a festa, decisão tomada após reunião realizada em 2 de junho de 1986, na delegacia de polícia, envolvendo membros do Ministério Público, policiais militares e representantes da Secretaria Municipal de Cultura e dos grupos de bumbás. O resultado dos entendimentos, segundo Rodrigues (2006), foi divulgado por meio de uma nota oficial conjunta, que decretou a divisão geográfica da cidade, de acordo com as cores dos bumbás. Ficou estabelecido que a Rua Clarindo Chaves serviria como fronteira entre as áreas de predominância de cada associação. O território do Caprichoso seria a região que vai da referida via até o bairro da Francesa, e o do Garantido, a do mesmo marco até o bairro de São Benedito. Rodrigues (2006, p. 111) oferece outros dados relevantes sobre a questão:

Como toda regra, a medida compreendia algumas exceções para preservar o direito individual de cada cidadão e regulamentar o uso dos espaços público. Foi permitido às pessoas, respeitando o princípio da individualidade, ornamentar a fachada de suas propriedades com as cores do boi preferido, não importando o território onde a residência estivesse localizada. Em relação às praças públicas, as autoridades decidiram que os locais que já estavam enfeitados, deveriam continuar assim, sob a responsabilidade de quem as ornamentou. Ficaram estabelecidos também alguns campos neutros, ou seja, onde não poderia haver adornos de nenhuma associação, como a praça da catedral (de Nossa Senhora do Carmo), o porto e o aeroporto, sob a justificativa de não influenciar a preferência dos visitantes quando estes estivessem chegando à cidade.

O que esses fatos sobre o movimento de estetização da cidade revelam é que seu desenvolvimento foi atravessado por distintos interesses e valores, muitos dos quais se mostraram nocivos à sua continuidade e expansão. Hoje, a expressão pública das preferências em termos de bumbá não apenas é aceita como também é amparada por leis municipais, que transformaram definitivamente a rivalidade física em uma rivalidade, por assim dizer, poética, que faz uso da arte para a conquista de visibilidade e preponderância no espaço urbano.

Destacamos que a regulamentação dos trabalhos de ornamentação da cidade, somada a delimitação de "territórios" específicos para cada grupo de bumbá, permitiu que as manifestações de cunho estético e artístico se proliferassem de tal forma, junto às diferentes áreas da cidade, classes sociais e gostos, que se tornou corrente a crença em uma "cidade dividida em vermelho e azul", ideia que, inclusive, comparece em grande parte dos documentos produzidos, a partir 
da década de 1980, sobre a festa. As citações de Ricardo Biriba (2005) e Allan Rodrigues (2006) são, nesse caso, ilustrativas:

Estes dois grupos [Garantido e Caprichoso] atraíram de forma tão contundente a população, que a cidade dividiu-se em duas partes bem definidas, identificadas também pelas desigualdades sociais que delimitam a cidade. As cores azul e vermelho, correspondentes a cada agremiação folclórica, passam a determinar os seus territórios, em decorrência da rivalidade entre os bois e os aficionados desta brincadeira. (BIRIBA, 2005, p. 127)

Quem vai a Parintins deve compreender que ela é uma cidade dividida ao meio por duas paixões: uma em vermelho pelo Garantido e outra em azul pelo Caprichoso. O embate entre os bumbás envolve toda a população da Ilha e, mesmo aqueles que afirmam ser neutros ou 'Garanchosos', acabam sendo atingidos de uma forma ou de outra pela rivalidade existente entre os torcedores. (RODRIGUES, 2006, p. 105-106)

Pontuamos que essa notável projeção alcançada pelo movimento de estetização da cidade não passou despercebida aos olhos dos agentes externos, como a prefeitura da cidade, a Coca-Cola e a Empresa de Tintas Suvinil, que, nutridos de interesses comerciais e turísticos, já tentaram - e ainda tentam - interferir ou mesmo controlar a configuração e os rumos do movimento, através da introdução e massificação de suas próprias formas e temas. Mas os efeitos, nesse sentido, foram pouco significativos e, portanto, incapazes de alterar o caráter comunitário do movimento.

Cremos que os dados expostos sobre o movimento de estetização da cidade são suficientes para o reconhecimento da força das relações entre a festa e a comunidade, e também da vocação da cidade de Parintins para o acolhimento de formas de cunho artístico que desconhecem limites temporais e espaciais. Passemos, agora, para o detalhamento dessas formas, concentrando nossa atenção nos painéis figurativos.

\section{Os painéis figurativos e seu alimento temático}

Os painéis pintados e esculpidos são, sem dúvida, as realizações artísticas mais excepcionais introduzidas no espaço urbano parintinense. Embora mais dispendiosos e laboriosos, quando comparados a outras manifestações, esses painéis têm se multiplicado nas últimas décadas, passando a se fazer presentes tanto na zona central da cidade, no "circuito da festa", onde se percebe uma maior 
concentração de exemplares, quanto em sua periferia, onde os casos se mostram isolados, mas, ainda assim, eficientes no despertar da percepção, anestesiada pela monotonia do fluxo, dos moradores e turistas.

Fachadas, frontões e muros de residências e unidades comerciais, especialmente lojas, hotéis e pousadas, constituem as superfícies mais usada. (Figuras 2, 3 e 4). Geralmente desprovidas de interesse, essas áreas da arquitetura e de seu entorno imediato são tomadas para a criação de obras artísticas, cujas cores, contornos, relevos animam permanentemente o ambiente, rompendo com a rotina visual da cidade. Não devemos pensar, no entanto, que a realização dos painéis se fecha nos citados pontos da arquitetura. Há casos em que a obra, tendo seu início marcado na fachada principal, se expande para as laterais, cobrindo toda a superfície disponível, num impulso de mascarar a aparência primeira da edificação e, ao mesmo tempo, assumir monumentalidade.

Resultando de um interesse individual, a produção dos painéis não se encontra subordinada a regras gerais, a não ser aquelas ligadas à técnica de feitura, ou seja, eles podem ser pintados, trabalhados em alto e baixo relevo ou ainda conjugar escultura e pintura, além de outras técnicas associadas à questão das exigências estéticas próprias da festa, que, como dissemos, instituiu alguns símbolos e temas básicos para cada grupo de bumbá. Outros aspectos, como local de disposição da obra, dimensões e acréscimo de temas, costumam ser definidos pelo proprietário, em conversa ou não com os artistas que efetuarão o trabalho. O próprio modo de representação é um aspecto que independe de regras, uma vez que os painéis são feitos por diferentes artistas, em geral, ligados à Associação de Artistas Plásticos de Parintins (AAPP) e que, portanto, apresentam estilos diferentes.

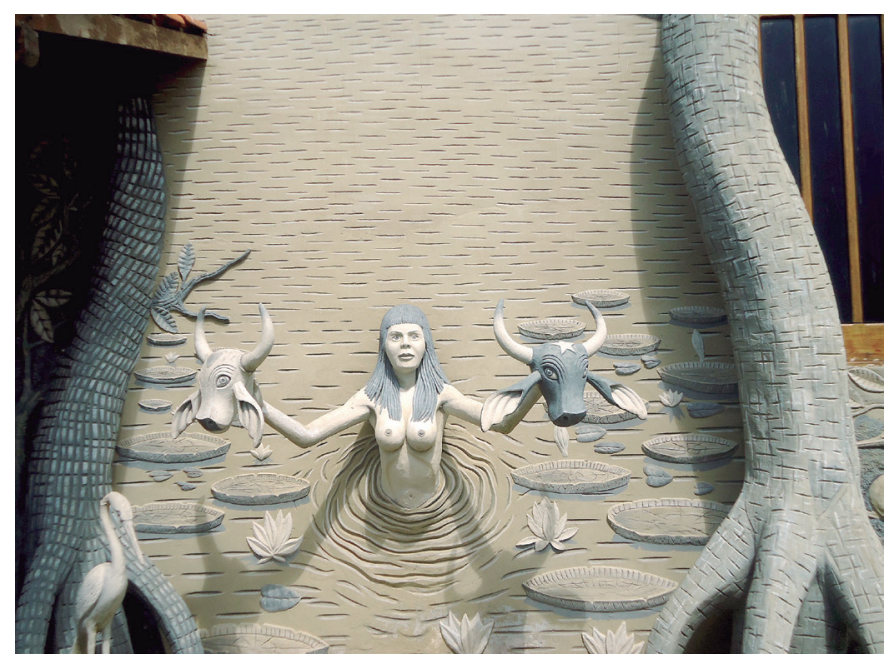

Figura 2 - Painel esculpido na fachada de Pousada Fotografo: Marivaldo Bentes (2013). 


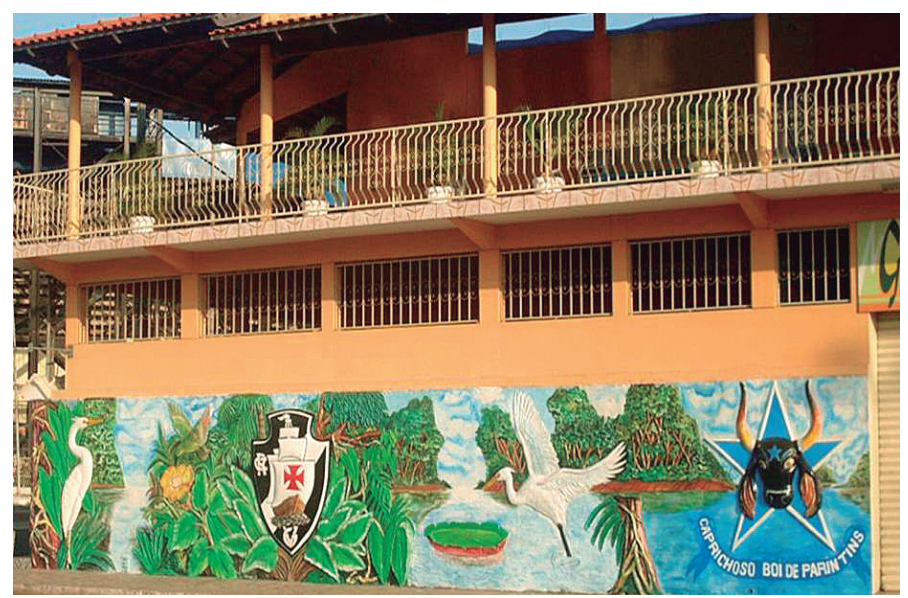

Figura 3 - Muro esculpido e pintado de residência Fotógrafo: Leandro Bentes (2013).

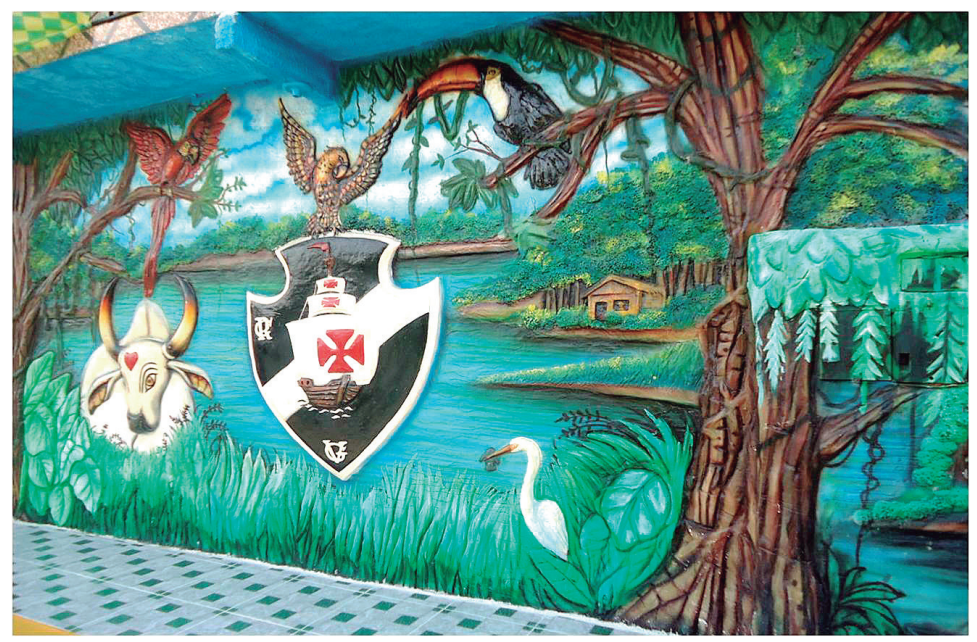

Figura 4 - Fachada esculpida e pintada de residência Fotógrafo: Marivaldo Bentes (2013).

Falemos agora das representações dos painéis. Pelo fato de constituírem realizações apegadas ao figurativismo, os painéis determinaram a primazia no "tema", noção que vai além do uso de elementos ligados ao bumbás e que comunicam as preferências do proprietário, a exemplo da figura do boi Alegórico, representado parcial (cabeça) ou integralmente (corpo inteiro), acompanhada de seus atributos: figura do coração, no caso, do bumbá Garantido, e a estrela, quando se trata do Caprichoso. Ou seja, além destes elementos, imprescindíveis para o reconhecimento dos vínculos dos painéis com a festa, outros temas costumam colaborar 
para a dinâmica e expressividade das composições, mas sem comprometer o caráter fortemente unitário do movimento. A natureza é um desses temas.

É praticamente impossível encontrar um painel na cidade de Parintins em que a representação da natureza esteja ausente. Mesmo naquelas realizações menos sofisticadas, mais intuitivas e com pouco rigor artístico, que revelam uma destacada preocupação com o aproveitamento de sua imediatez e capacidade de comunicação, elementos relacionados ao mundo natural são identificáveis, sugerindo resultar de um apreço generalizado pelo tema. A propósito, para tornar a natureza reconhecível, os artistas se apropriam da vegetação nativa, que lhes oferece uma diversidade de árvores e plantas, e da fauna, de onde são extraídas onças, pássaros, botos e outros animais característicos da região. Também se apropriam do "mundo das águas" e o presentificam por meio de "recortes" de rios e igarapés, cerceados por indicativos de vegetação metodicamente organizados.

Do ponto de vista da natureza, é possível falar dos painéis como "cartões postais", que dão visibilidade às qualidades naturais da região amazônica, privilegiando aqueles componentes que consideram particulares e emblemáticos. Estes, aliás, costumam ser tratados dentro de uma perspectiva idealizada e, ao mesmo tempo, contemplativa, que propõe o encontro entre o idílico, o bucólico e o desejável. Disso, tem resultado uma espécie de convenção, em termos de representação, que prega a construção de um mundo embebido pelo verde da floresta, livre de contaminação e também da presença do homem, em que árvores, flores, rio, animais e outros pormenores extraídos da natureza convivem harmoniosamente, sem riscos aparentes, ilustrando, assim, a ideia de "paraíso amazônico", que ainda abastece os discursos midiáticos e povoa o imaginário de brasileiros e estrangeiros.

Frente à relevância atribuída à paisagem natural na constituição dos painéis figurativos, que, em alguns casos, lhe permite assumir o protagonismo da composição, algumas indagações parecem oportunas: o que explicaria a presença insistente e destacada de elementos da natureza nos painéis? Seria simplesmente um desinteresse dos artistas ou, antes disso, dos proprietários pela paisagem urbana? A preferência por uma representação de uma natureza idílica seria apenas resultado de uma tendência decorativista? Talvez, uma breve consulta na valorização dada a questão do meio ambiente na festa dos bumbás Garantido e Caprichoso seja capaz de lançar luz sobre estes questionamentos.

\section{Os bumbás de Parintins e seu discurso preservacionista}

A consolidação das apresentações oficiais dos bumbás, na arena do bumbódromo, como acontecimentos temáticos, ocorrida gradativamente ao longo de sua evolução, abriu espaço para que a cultura da região assumisse grande importância e, desse modo, o bumba meu boi, que se encontra na base da manifestação, 
deixou de constituir o centro de interesse dos produtores da festa. Assim, as culturas indígenas, a vida dos ribeirinhos, a história da região amazônica, seus heróis e fatos marcantes e a natureza se transformaram em material temático básico da produção artística dos bumbás, influenciando desde a composição de toadas à feitura de alegorias.

Importa-nos destacar que o desdobramento da festa para um horizonte amazônico não resultou apenas em uma apresentação espetacularizada de tais temas, em que os estereótipos, as simplificações e os aspectos positivos são priorizados. Num impulso de enfraquecer a ideia de que a festa não é momento para reflexão, os gestores dos grupos de bumbás, já há algum tempo, têm oferecido espaço para a discussão das problemáticas históricas e da situação atual dos temas de que se apropriam, em especial, do índio e do meio ambiente.

Sem pretender discutir de maneira aprofundada os fatores que propiciaram o aparecimento dessa visão crítica, pontuamos que, no caso das questões ambientais, que nos interessam particularmente, a mudança de abordagem surgiu, segundo Rodrigues (2006), como consequência da projeção alcançada pelo tema do meio ambiente no cenário mundial, a partir do final da década de 1980, período que marca a intensificação dos debates públicos e as atuações dos movimentos ativistas, como o Greenpeace. Toda essa movimentação externa, segundo o autor, não apenas era acessada pelos produtores da festa parintinense, sobretudo por meio da televisão, como também passou a ser gradativamente introduzida no espaço da festa, por meio de suas realizações artísticas. Gerson Severo Dantas (2003, p. 42) nos oferece a seguinte contribuição:

A noção de natureza que os bois tinham ao serem criados, na década do século passado, é uma noção de natureza inesgotável, que está aí para ser explorada, ou seja, bastava o caboclo trabalhar que a natureza tudo providenciava. Já em 1989, quando o Caprichoso leva para a arena o tema 'A força da Natureza' e apresenta uma alegoria retratando o seringueiro Chico Mendes, que havia sido assassinado por fazendeiros no Acre, nota-se uma mudança dessa visão. Essa homenagem marca um momento significativo, pois Chico Mendes, que a maioria das pessoas não conhecia no Brasil até ser morto, havia ganho o prêmio Global 500, uma comenda importante na área dos defensores da ecologia.

Seja como consequência desse turbulento cenário ou de qualquer outro fator externo, o fato é que um verdadeiro movimento de reformulação de ideias se processou nos domínios da festa, evidenciando certo interesse em transformá-la numa espécie de instrumento de denúncia social, interessado em converter a ilusão cênica em consciência crítica. 
E esse movimento parece ganhar contornos mais definidos a cada edição. Os temas centrais, por exemplo, escolhidos na última década, confirmam isso. Enquanto o bumbá Garantido teve suas apresentações idealizadas a partir de temas como "Amazônia viva" (2001); "Garantido, o boi da Amazônia" (2002); "Amazônia, santuárioesmeraldas" (2003); "Amazônia, pátria verde" (2004); "Amazônia em aquarela" (2005); "A grande maloca" (2006); "Guardiões da Amazônia” (2007); "Garantido: o boi da preservação" (2008), os produtores do bumbá Caprichoso fizeram propaganda do estado de suas reflexões através de temas como "Amazônia quaternária" (2001); "Amazônia,cabocla de alma indígena" (2002); "Amazônia: terra do folclore; fonte de vida" (2004); "Amazônia solo sagrado" (2006); "O El dourado é aqui" (2007); "Parintins: onde o verde encontra o azul” (2009).

Não é preciso uma análise minuciosa do panorama acima para perceber que os temas centrais foram colocados a serviço de um objetivo específico e ambicioso, no caso, apresentar os bumbás Garantido e Caprichoso, diante de seus consumidores, como grandes "defensores" da Amazônia. Isso significa que a produção artística em geral passou a estar totalmente voltada para a afirmação dos novos discursos, sendo utilizada, como nunca, para tornar as problemáticas regionais acessíveis a todos. Diante dessa chamativa representatividade alcançada pelo tema do meio ambiente no contexto das apresentações espetacularizadas de Garantido e Caprichoso e a própria projeção, portanto, das possibilidades de massificação que estas apresentações oferecem ao tema, além dos discursos que o envolvem na arena, poderíamos, de algum modo, relacionar a realidade conceitual da festa dos bumbás com a realidade conceitual dos painéis figurativos e, assim, localizar explicações mais densas para a recorrência do tema da natureza? $\mathrm{Na}$ seção seguinte, ensaiamos uma resposta.

\section{Painéis figurativos e discurso preservacionista: uma relação possível?}

Em nossa opinião, os inúmeros estímulos e mensagens associadas ao meio ambiente, oferecidas pelas apresentações dos bumbás, ajudaram a formar um pensamento local de valorização da natureza, que fez dos painéis pintados e esculpidos, dispostos no espaço público e também no domicílio privado, seu canal, por excelência, de divulgação, sobretudo, porque o figurativismo, que é característico dessas realizações, permitia a imediata apreensão do tema. Naturalmente, não estamos falando de uma transformação coletiva de mentalidade, capaz de levar, por exemplo, a alterações drásticas de práticas cotidianas (entendidas como antiecológicas) ou mesmo ao ativismo, mas de um reconhecimento público da importância do meio ambiente, que é a própria realidade na qual a comunidade está imersa. 
Com efeito, a natureza se faz presente dentro e no entorno da cidade. O Rio Amazonas banha seu frontispício, e suas ramificações, que geram pequenos rios e lagoas, como a da Francesa, a contornam totalmente, ressaltando sua condição de ilha. Dessas águas, são tirados (hoje, com certa dificuldade) os peixes que se encontram na base da economia local e alimentam inúmeras famílias que dependem unicamente da pesca.

A mata nativa, embora bastante alterada no perímetro da cidade e suas imediações, ainda apresenta alguns focos de resistência que possibilitam a contemplação de seu modo sumário de existência. Esses focos se encontram, por exemplo, nas áreas suburbanas do Parananema, Aninga e Macurany, onde existem lagos e uma vegetação extasiante, totalmente acessível aos moradores da zona urbana. O que estamos tentando demonstrar com isso é que uma dissociação entre a imagem da cidade e a imagem da natureza é algo impensável, e que somos persuadidos a entender a vida diária da população e as possibilidades que o meio natural oferece, em termos de subsistência, de divertimento, de contemplação, entre outros, como realidades que se imbricam e se influenciam mutuamente.

Esses inúmeros vínculos entre a comunidade parintinense com a natureza, permeados de interesses e sentimentos diversos, já seriam, ao nosso ver, justificativa para a introdução do meio natural no repertório temático dos painéis figurativos, assim como podem ter contribuído para o seu ingresso, como subsídio de criação, no contexto da produção artística diretamente associada à festa de Garantido e Caprichoso. Mas insistimos na ideia de que, além dessa inclinação natural para a valorização da natureza como tema, as artes urbanas seriam influenciadas pelos conteúdos das apresentações dos bumbás. Nesse sentido, a presença da natureza nos painéis figurativos seria responsável por filiá-los a um dos veios que os produtores dos grupos têm explorado com frequência e fecundidade: a preservação ambiental. Esta mesma filiação, acreditamos, também poderia explicar a predominância da representação da natureza como um mundo pacífico, fértil e, sobretudo, livre de contaminações e da interferência da mão humana.

É possível reforçar nosso ponto de vista, recorrendo a alguns comentários de Canclini (1980) sobre a função social da arte. O autor argumenta que a reação da arte sobre a sociedade não é, integralmente, do mesmo caráter dos condicionamentos que a sociedade exerce sobre a arte. "Os condicionamentos sociais são regidos por leis, pertencem ao campo da necessidade; a ação da arte, como toda ação transformadora, procura ir além das leis, está condicionada pela necessidade, mas trata de abrir nela um lugar para o possível”. (CANCLINI, 1980, p. 32) Em nossa opinião, o "possível" a que o autor se refere está relacionado àquelas implicações da arte que não foram consideradas e muito menos previstas pelo artista no momento da produção. Essas implicações revelariam que os efeitos 
do fenômeno artístico desconhecem limites, podendo influenciar livremente os sentimentos, as ideias e o comportamento dos indivíduos para os quais se dirige, não ficando, assim, restritos ao mero ato contemplativo.

Aproximando essas reflexões do novo horizonte descortinado pela festa dos bumbás, defendemos que os resultados alcançados pelos produtores dos bumbás foram além de qualquer objetivo que estes pudessem imaginar para suas ações, introduzindo, no seio da comunidade parintinense, um gosto, ainda pouco refletido, pela expressão, por meio de representações artísticas no espaço público, de sua relação com a natureza e da importância que ela possui na vida local. Uma possível prova do que estamos defendendo é dada por um grupo crescente de painéis surgidos nos últimos anos em Parintins que, embora seguindo as sugestões técnicas de representação e de locais de disposição oferecidas pelos painéis associados à festa de Garantido e Caprichoso, não pretendem estabelecer a mesma vinculação com os grupos. Por isso, dispensam os símbolos que aludem aos bumbás. Este conjunto emergente de painéis fala, a partir do idioma do figurativismo, das atividades de subsistência locais, da forte ligação com a cultura indígena, da história local, de outras práticas festivas, privilegiando, como elemento constante, o tema da paisagem amazônica, representada dentro das mesmas convenções identificadas nos painéis ligados à festa dos bumbás.

\section{Considerações finais}

Como anunciamos, este artigo constitui um ensaio sobre as representações figurativas das artes urbanas parintinenses, associadas aos bumbás Garantido e Caprichoso, que deve ser tomado como ponto de partida para reflexões mais aprofundadas. Apesar disso, sua importância não deve ser reduzida à descrição e à classificação do movimento de estetização da cidade e de suas manifestações constituintes. Do mesmo modo, a análise que aqui realizamos, uma das poucas investidas sobre o tema, precisa ser destacada como empreendimento que avança na compreensão das artes urbanas parintinenses, especialmente por dirigir-se ao mundo subjacente destas realizações e tentar reunir alguns possíveis significados e mensagens, denunciados ou não por sua realidade apreensível.

Como resultado parcial de nossa análise, consideramos as pinturas e esculturas dispostas nas edificações da cidade como realizações portadoras de densa carga de significados, que obstaculizam qualquer tentativa de fechar as razões de sua existência no mero decorativismo e entretenimento. E, ainda que sua ligação, ou, melhor, sua subordinação à festa seja seu aspecto mais característico, aquele que desejar aprendê-las teoricamente deverá considerar - mesmo sem manifestar tal consideração - sua capacidade de esclarecer outros valores, intenções, expectativas e devaneios dos grupos que as produzem. De outro modo, este pesquisador 
estará colaborando para o esvaziamento da carga semântica dessas realizações e, por conseguinte, para a desqualificação das possibilidades da arte de atuar como operação comunicativa, ação no espaço cotidiano da vida e signo social.

Uma última consideração: o modo como procedemos à análise das representações figurativas dos painéis informa nossa dívida com o método panofskyano, este que, embora participando de maneira velada na constituição de nossa abordagem, ofereceu orientações fundamentais para que nosso entendimento do tema fosse construído a partir do tratamento individualizado de suas particularidades e dentro de uma visão que induzia a superação do nível, por assim dizer, epidérmico da compreensão das obras em questão para alcançar camadas mais profundas, não objetivas. Isso explica porque, ao determos nossa atenção nos painéis, iniciamos pela descrição dos aspectos emanados por sua materialidade, passando pela identificação de seus temas para, só então, alcançarmos o domínio de seus significados e mensagens, etapa em que pudemos levantar algumas possibilidades de interpretação, cuja validade poderá ser questionada em estudos posteriores.

\section{Referências}

BIRIBA, R. B. Parintins cidade ritual: boi-bumbá, performance e espetacularidade. 2005. 385 f. Tese (Doutorado em Artes Cênicas) - Escola de Teatro, Universidade Federal da Bahia, Salvador, 2005.

CANCLINI, N. G. A socialização da arte: teoria e prática na América Latina. Tradução de Maria Helena Ribeiro da Cunha e Maria Cecília Queiroz Moraes Pinto. São Paulo: Cultrix, 1980.

DANTAS, G. S. de O. O boi-bumbá de Parintins como fenômeno de comunicação de massa: um estudo da recepção das mensagens ecológicas veiculadas por Garantido e Caprichoso no Festival de Parintins de 2002. 2003. Dissertação (Mestrado Sociedade e Cultura na Amazônia) - Instituto de Ciências Humanas e Letras, Universidade do Amazonas, Manaus, 2003.

HOLLY, M. A. Panofsky and the foundations of art history. Ithaca, N.Y.: Cornell University Press, 1984.

LIMA, S. Toadas, bandeiras, gritos e cores:é festa em Parintins. Jornal do Comércio. Estudos \& Pesquisas, Parintins, n. 1, Jun. 1989.

SILVA, M. B. da. A espetacularização da festa do boi-bumbá de Parintins: novos modos de produção artística. 2009. 141 f. Dissertação (Mestrado em Artes Visuais) - Escola de Belas Artes, Universidade Federal da Bahia, 2009.

PANOFSKY, E. Significado nas artes visuais. São Paulo: Perspectiva, 2004.

RODRIGUES, A. S. B. Boi-bumbá: evolução: livro-reportagem sobre o Festival Folclórico de Parintins. Manaus: Editora Valer, 2006. 